Presented at: 1997 International Free-Electron Laser Conference

Beijing, China

August 18-22, 1997

$$
\text { CONF-970885 - }
$$

High-Yield Metal Materials for Photocathode RF Gun

X. J. Wang, I. Ben-Zvi, J. Smedley, T. Srinivasan-Rao, M. Woodle

National Synchrotron Light Source, Accelerator Test Facility, Brookhaven National

Laboratory, Upton, NY 11973-5000

D.T. Palmer and R.H. Miller

Stanford Linear Accelerator Center, Stanford, CA 94309

\author{
REC FI: \\ FFR 10998 \\ OSTI
}

November 1997

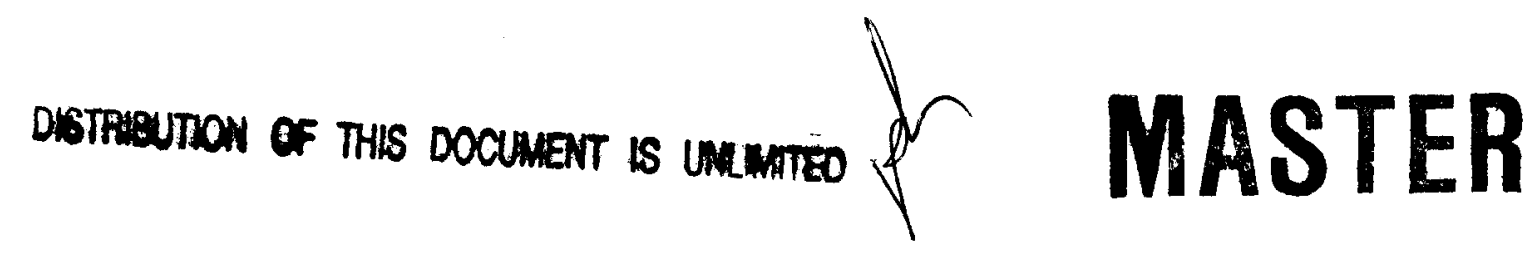

National Synchrotron Light Source

Brookhaven National Laboratory

Upton, NY 11973

Work performed under the auspices of the U.S. Department of Energy,

under contract DE-AC02-76CH00016 


\section{DISCLAMMER}

This report was prepared as an account of work sponsored by an agency of the United States Government. Neither the United States Government nor any agency thereof, nor any of their employees, makes any warranty, express or implied, or assumes any legal liability or responsibility for the accuracy, completeness, or usefulness of any information, apparatus, product, or process disclosed, or represents that its use would not infringe privately owned rights. Reference herein to any specific commercial product, process, or service by trade name, trademark, manufacturer, or otherwise does not necessarily constitute or imply its endorsement, recommendation, or favoring by the United States Government or any agency thereof. The views and opinions of authors expressed herein do not necessarily state or reflect those of the United States Government or any agency thereof. 


\title{
High-Yield Metal Materials for Photocathode RF Gun
}

\author{
X.J. Wang, I. Ben-Zvi, J. Smedley, T. Srinivasan-Rao and M. Woodle \\ Brookhaven Accelerator Test Facility, BNL, Upton, NY 11973, USA \\ D.T. Palmer and R.H. Miller \\ Stanford Linear Accelerator Center, Stanford, CA 94309
}

Abstract

Significant progress has been made in both improving the quantum efficiency and understanding the physics process of photoemission of metal photocathode materials under high electric field. Metal material, copper and magnesium were installed on the photocathode RF gun, and experimentally investigated using frequency quadrupled Nd: Yag laser $(266 \mathrm{~mm})$. A systemic procedure was developed for preparing cathode; this involves diamond polishing, ultrasonic cleaning and high-temperature vacuum bake out. Using laser cleaning and explosive electron emission cleaning, the highest quantum efficiency measured for copper and magnesium are $0.02 \%$ and $0.3 \%$, respectively. The Schottky effect was experimental investigated, the quantum efficiency of the $\mathrm{Cu}$ is dominated by the Schottky effect since the work function of the copper is almost equal to the photon energy used (4.66 eV). The quantum efficiency of the magnesium is significant enhanced by the Schottky effect.

\section{Introduction}

One of the major improvements in the last few years in photocathode RF gun technology is the development of CST cathode [1], the life time of the semiconductor was extended from days to weeks. But stringent vacuum condition and other considerations limit semiconductor cathode's applications. Rapid developments in laser technology, such as diode pumped laser system and high efficiency nonlinear crystal [2], made it using relative low quantum efficiency (Q.E.) metal cathode more attractive and practical, because its robust and long life time. One of the major challenges in using metal cathodes in photocathode RF gun is its inconsistency in $Q E$ measurements and $\mathrm{QE}$ improvement technology. We will report the progress have been made in the last few years in metal cathode materials, such as Copper and Magnesium, at the Brookhaven Accelerator Test Facility (ATF).

We will first present the procedure of preparing the metal cathodes for photocathode RF gun, and experimental results of $\mathrm{QE}$ measurements for both Copper and Magnesium cathodes. One of the most important effects in photoemission from metal material is the Schottky effect, we will present the experimental measurement of the Schottky effect on both Copper and Magnesium cathode, discuss its application and effect on the performance of the photocathode RF gun.

\section{Experimental Measurements.}

The quantum efficiency measurements for both Copper and Magnesium were made in the photocathode RF gun several years ago $[3,4]$. Since then, several labs have reported large variation in their QE measurement for both Copper and Magnesium cathodes. We have developed a procedure of preparing the metal cathode for photocathode RF gun applications, which enable us consistently produce reasonable results. The cathode preparation involves several steps. The initial ultrasound cleaning in the alcohol bath remove any contamination on the cathode surface left from cathode manufacture. Then cathode surface was polished using using three different size diamond polishing compound, as polish progressing, the diamond sizes in the polishing compound were reduced from $9 \mu \mathrm{m}, 6 \mu \mathrm{m}$ to $1 \mu \mathrm{m}$. The polished surface was rinsed with Hexane before immersed in the Hexane bath for 20 minutes ultra-sound cleaning. After the cathode surface was blowed dry with dry nitrogen, it was placed inside a UHV vacuum chamber for bake out. The bake out usually lasts about a week. The cathode was install on the 1.6 cell photocathode RF gun [5] developed by the BNL/SLAC/UCLA collaboration under dry nitrogen.
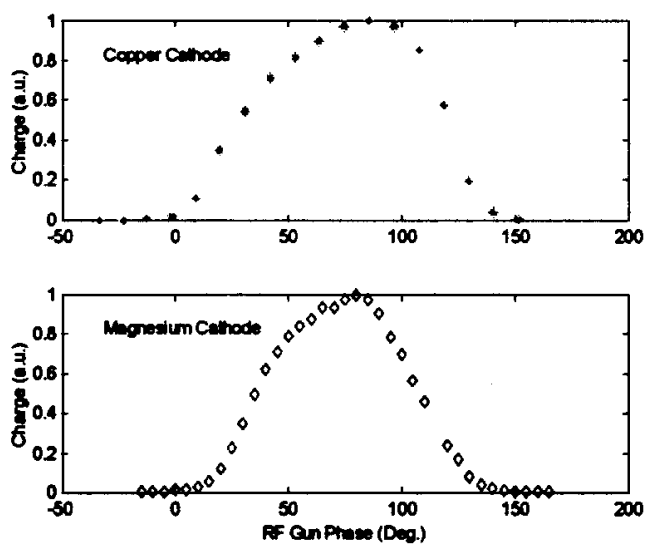

Fig. 1 The measured photoelectron charge as function of the $\mathrm{RF}$ gun phase for $\mathrm{Cu}$ and $\mathrm{Mg}$ cathodes.

The photocathode of the RF gun at the ATF was driven by a frequency quadrupled (266 nm) Nd: Yag laser system. A small fraction of the laser energy was splitter off allows us monitor both the laser energy and spot size on the cathode. The charge was measured using a Faraday cup half-meter down stream of the RF gun. The solenoid magnet at the exit of the RF gun can be used to focus the photo electron beam on to the Faraday cup for charge measurement. Since the work functions for both Copper (4.0 - 4.6 $\mathrm{eV})$ and Magnesium $(3.7-4.1 \mathrm{eV})$ are close to the 
photon energy of the frequency quadrupled Nd: Yag laser (4.66 eV), the $\mathrm{QE}$ measurement is the strong function of the RF gun phase (i.e. the instant electric field) when laser strikes the cathode. Fig. 1 shows that both $\mathrm{Cu}$ and $\mathrm{Mg} \mathrm{QE}$ measurements as the function of the RF gun phase.

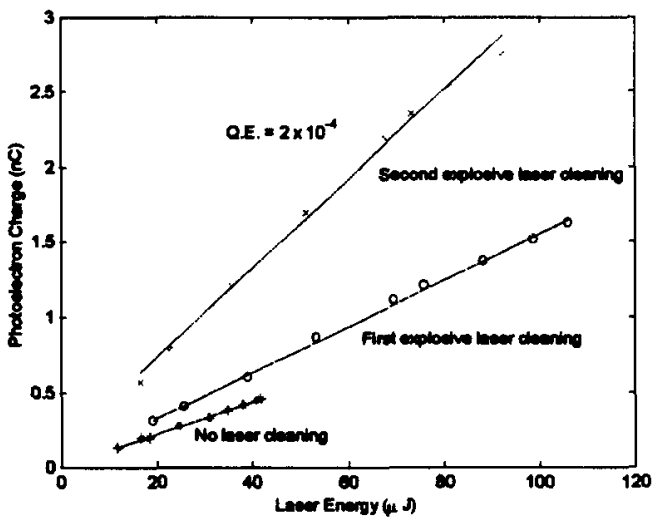

Fig.2 $\mathrm{QE}$ measurements for $\mathrm{Cu}$ cathode before and after the explosive laser cleaning.

The QE measurement for the Cu cathode at $90^{\circ}$ of the RF gun phase is plotted on Fig.2. The initial $Q E$ without any laser cleaning is about $2 \times 10^{\wedge}(-5)$. To further improve the $Q E$, we adopted so-called explosive laser cleaning. By reducing the laser spot to 0.3-mm diameter, with $50 \mu \mathrm{J}$ laser energy, the laser induced explosive electron emission will occur [6]. After first explosive laser cleaning, more than a factor of two improvements in $\mathrm{QE}$ was observed. We also observed an order of magnitude variation in $\mathrm{QE}$ on the cathode surface (2-mm diameter). After several more cleanings, we reduced the $\mathrm{QE}$ variation on the cathode surface to less than $50 \%$, and measured $\mathrm{QE}$ is about one order magnitude improvement over the initial QE $\left(2 \times 10^{\wedge}(-4)\right)$

Fig.3 shows the QE measurement for a $\mathrm{Mg}$ cathode. $\mathrm{Mg}$ cathode is made of $99.8 \%$ pure magnesium cylinder with half-inch diameter, it was press fit on to the copper. It took more than a week of RF conditioning for the $\mathrm{Mg}$ cathode to reach the Normal $\mathrm{RF}$ gun operating field gradient of $100 \mathrm{MV} / \mathrm{m}$. The initial $Q E$ of the magnesium cathode is less than That Cu's, we attributed that to the oxidation of the $\mathrm{Mg}$ surface. We first cleaning the cathode with laser only, the laser energy used is about $15 \mu \mathrm{J}$ for a laser spot diameter of $0.3 \mathrm{~mm}$. Almost a factor of two improvement of $\mathrm{QE}$ was measured. Then we turn on the RF power (with field gradient on the order of 30 $\mathrm{MV} / \mathrm{m}$ ), and $25 \mu \mathrm{J}$ laser energy, we were able to clean the cathode using explosive laser Cleaning

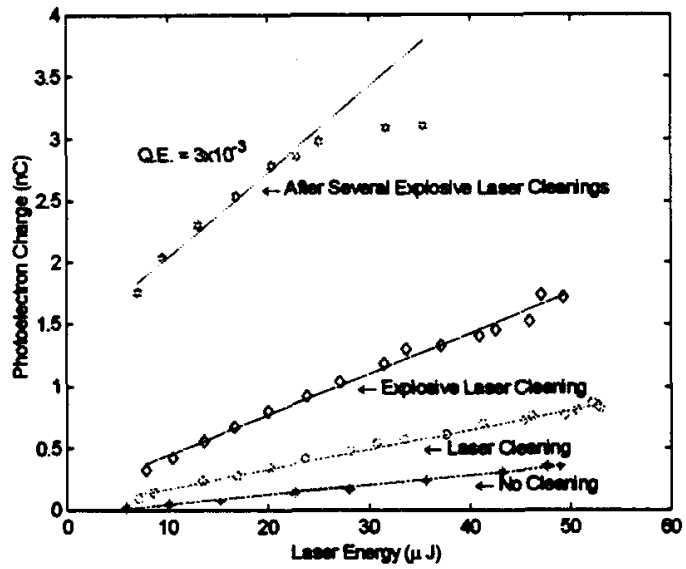

Fig.3 QE measurements for bulk $\mathrm{Mg}$ cathode before and after laser cleanings.

technique. After several laser explosive cleanings, the variation of $\mathrm{QE}$ over the cleaning surface is less than $50 \%$, and the best $\mathrm{QE}$ measured is $0.3 \%$. The $\mathrm{QE}$ decayed to about $0.1 \%$ in eight hours. And it took several weeks for $\mathrm{Mg} \mathrm{QE}$ decay to about $0.04 \%$. We always be able to restore the $\mathrm{Mg} \mathrm{QE}$ to $0.1 \%$ with explosive laser cleaning.

We have observed that the joint of the press fit of $\mathrm{Mg}$ on the $\mathrm{Cu}$ is one of the main cause for RF break down in the RF gun, this limits the field on the cathode to about $100 \mathrm{MV} / \mathrm{m}$. We also explored other technique of mounting the $\mathrm{Mg}$ on the $\mathrm{Cu}$ cathode plate. One technique we used is sputtering a thin layer of $\mathrm{Mg}$ on the $\mathrm{Cu}$ cathode $(20 \mu \mathrm{m})$. It was measured that the damage threshold for sputtered $\mathrm{Mg}$ is more than twice high than bulk Mg. Fig.4 shows $\mathrm{QE}$ measurement for sputtered $\mathrm{Mg}$ before and after laser cleaning without RF on. One interesting feature we observed, that the $\mathrm{QE}$ of sputtered $\mathrm{Mg}$ decay much faster than bulk $\mathrm{Mg}$ (fig.5).

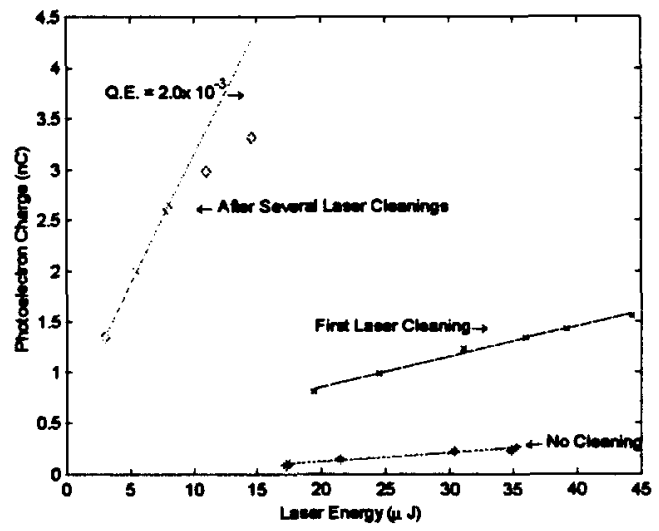

Fig.4 QE measurements for sputtered $\mathrm{Mg}$ cathode before and after laser cleanings. 


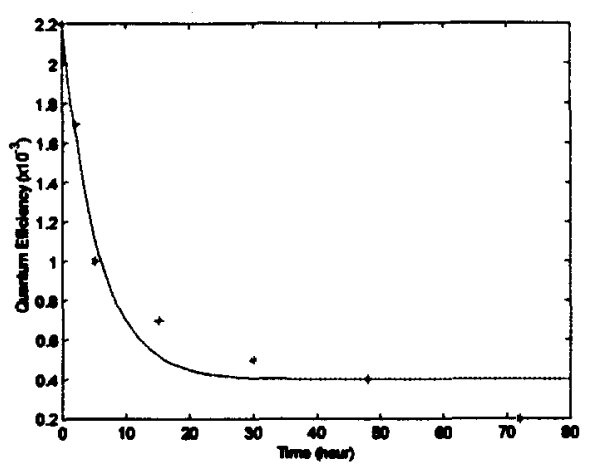

Fig.5 the QE lifetime measurement for sputtered $\mathrm{Mg}$ cathode.

III. The Schottky Effect

The photoelectron current density can be described by the following formula [7],

$j=A I(t)(h v-\varphi+\alpha \sqrt{\beta E(t)})^{2}$

Where I $(t)$ is the time dependent laser intensity, $h v$ is the photon energy, $\varphi$ is the work function of the cathode material, and $\beta>1$ is so-called field enhancement factor, and $E(t)$ is the instantaneous electric field on the cathode. For metal cathode used, the photon energy and work function is close, so the time dependency of the photoelectron beam will strongly depend on the instantaneous electric field. Fig. 1 shows that, for both $\mathrm{Cu}$ and $\mathrm{Mg}$, the charge of the photoelectron beams were determined by the RF gun phase. This clearly shows that, the Schottky effect plays important role in photoemission process of the metal cathode in the RF gun.

The schottky effect not only affect the $Q E$ of photoemission (Fig.1), it also plays important role in charge distribution inside the photoelectron bunch and space charge effects. For example, Fig. 3 shows that the QE change dramatically for high charge situation due to the space charge field. And this implies that the later part of the charge of photoelectron bunch is suppressed by the space charge induced Schottky effect. This will change the bunch length of the photoelectron beam and dynamic process inside the photocathode RF gun (Fig.6).

The schottky effect can be used to determine the absolute RF gun phase relative to the laser. The most important application for this effect maybe, the longitudinal distribution shaping of the photoelectron beam by adjusting the relative phase between the laser and $\mathrm{RF}$ gun for a fixe charge.
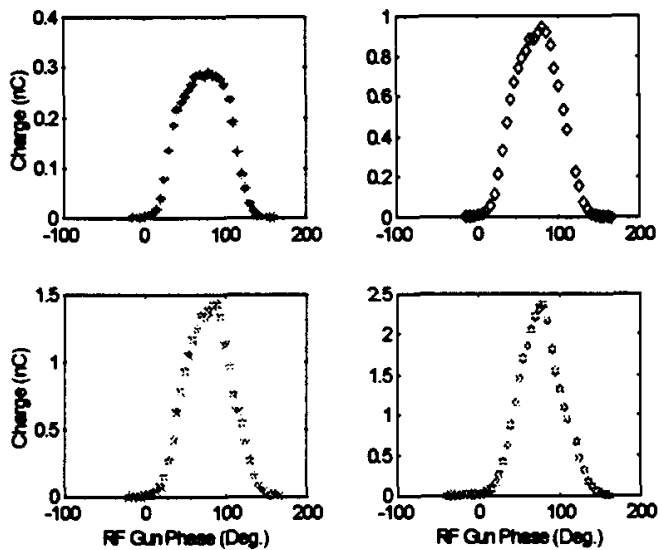

Fig.6 The photoelectron charge as the function the $R F$ gun phase for four different laser energies.

\section{Acknowledgments}

Authors acknowledge the technical support provided by ATF staff, B. Cahill, R. Harington, R. Malone, M. Montegmago and J. SChill made it possible for this experiment. This work is supported by the U.S. Department of Energy under contract No. DE-AC02$76 \mathrm{CH} 00016$.

1. P. Michelato, Nucl. Instr. and Meth. in Phys Res. A393 (1997) 455-459.

2. Y.K. Yap et al, Opt. Lett. 21,1348 (1996).

3. X.J. Wang et al,Nucl. Instr. and Meth. in Phys Res. A356 (1995) 159-166.

4. X.J. Wang et al, Nucl. Instr. and Meth. in Phys Res. A 375(1996) 82-86.

5. D.T. Palmer, X.J.Wang et al, AIP Conference Proceeding 398 (1997), 695-704.

6. X.J. Wang et al, J.Appl. Phys. 72( 1992), 888894.

7. M. Cardona and L. Ley, Photoemission in Solid I, edited by M. Cardona and L. Ley (SpringerVerlag, NY, 1978), p22. 
M98002640

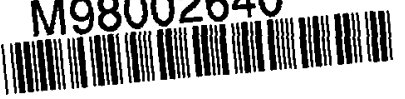

Report Number (14) BNC- $\frac{B 5002}{\text { CONF }-970885--}$

subl. Date (11) 199711

sponsor Code (18) DOE/ER, XF

DOE 